\title{
El Historiskerstreit chileno, ensayo sobre los rendimientos políticos de la patrimonialización de la memoria
}

The Chilean Historiskerstreit, essay on political yields of patrimonialisation of memory

\author{
Sigal Meirovich \\ sigal.meirovich@gmail.com \\ Universidad Alberto Hurtado \\ Universidad Internacional SEK \\ Chile
}

\section{Resumen}

Tras episodios de terrorismo de Estado que han dejado heridas abiertas y antagonismos irresolubles, la integración social y construcción de comunidad nacional requiere de políticas que mantengan la reflexión (y por ende la controversia) viva. Tal como encendiera el debate el historiador alemán Ernst Nolte durante el cuadragésimo aniversario del fin de la segunda guerra mundial, lo hace la ex directora de la Dirección de Bibliotecas, Archivos y Museos, Magdalena Krebs, justamente, durante el cuadragésimo aniversario del golpe militar en Chile. El presente ensayo no tiene por objetivo defender una posición en el conflicto sino más bien explorar una forma posible de mantener la controversia viva con el fin de probabilizar la construcción presente de una comunidad política capaz de incorporar críticamente sus conflictos sin caer en la hegemonía del consenso, pues ésta implica la generación constante de una memoria acallada en el otro lado de la distinción recordar/olvidar. La patrimonialización, en este contexto, aparece hoy como una alternativa posible. 
Palabras clave: Patrimonialización - Memoria - Política - Presentismo - Museo de la Memoria y los Derechos Humanos.

\begin{abstract}
After episodes of state terrorism that have left open wounds and irresolvable antagonism, social integration and community building requires national policies that maintain the reflection (and the controversy) alive. In the same way that the German historian Ernst Nolt ignited the debate, during the fortieth anniversary of the end of World War II, so does the former director of the Directorate of Libraries, Archives and Museums Magdalena Krebs, right, during the fortieth anniversary of the military coup in Chile. This essay is not intended to defend a position in the conflicto but rather to explore a possible way to keep the controversy alive for the present construction of a political community able to critically incorporate their conflicts without fall into the hegemony of consensus, as this involves ongoing production of a memory silenced on the other side of the distinction remember / forget. Patrimonial, in this context, appears today as an alternative.
\end{abstract}

Keywords: Patrimonialisation - Memory - Politics - Presentism - Museo de la Memoria y los Derechos Humanos.

\title{
Introducción
}

La memoria del Holocausto y la segunda guerra mundial se convirtieron en la base de la construcción de una nueva Europa. El exterminio los judíos sistemáticamente organizado y ejecutado por el Estado alemán se universaliza en la memoria social como un Crimen contra la Humanidad. En la Declaración Universal de los Derechos Humanos que deviene de esta catástrofe (1948) se establece el derecho fundamental a la vida como un derecho universal y cosmopolita. Esta lógica ha sido indispensable para el desarrollo de una cultura 
de los Derechos Humanos (DD.HH.) bajo el principio ético de Nunca Más, sin embargo, emerge en nuestra sociedad la necesidad de contar con una memoria multidireccional que no olvide el particularismo de ciertas memorias en pos de su universalización, a la vez que no relativice o minimice el crimen como un hecho particular sin relevancia para la humanidad completa (Baer, 2012).

Este modelo de universalización de la memoria es replicado en Chile desde el año 2010 con la inauguración de un espacio especializado en memoria y DD.HH. que ha sido criticado por los sectores políticos de derecha, pero también por los de izquierda, por descontextualizar el crimen. Sin embargo, el objetivo de esta decisión es muy claro; los derechos humanos son una categoría política necesaria para la construcción democrática, diferente del derecho individual como derecho judicial de cada ser humano. Norbert Lechner explica que:

La visión individualista permite disociar el orden político de la violación de los Derechos Humanos. Con lo cual, en Chile o Cuba, en USA o la URSS, las violaciones pueden ser por millares, pero no serían sino una suma de casos individuales y no una violación del grupo social. Por consiguiente, será compatible lamentar la violación de los Derechos Humanos en cada caso individual y, simultáneamente, exaltar el 'carácter profundamente democrático' del régimen en cuestión. Vale decir, la escisión liberal entre derechos individuales y orden social desvincula los Derechos Humanos de la política (Lechner, 1983).

Sin embargo, siguiendo a Lechner, los Derechos Humanos son un elemento constitutivo de la política, por lo que su violación es una agresión a la sociedad. Una política pública de los Derechos Humanos no pretende problematizar los hechos desde el conflicto de dos sujetos opuestos, sino desde la sociedad como sistema. Bajo la consigna de Nunca Más, expresión utilizada originalmente por los sobrevivientes del Gueto de 
Varsovia (Horestein y Silber, 2011), Justicia, Verdad y Memoria se articulan en función de la construcción política presente en la cual se debe asegurar a la ciudadanía que nunca más el Estado atentará contra sus propios ciudadanos bajo ningún contexto social, político ni económico.

Los avances de la última década en materia de DD.HH. son visibles en 5 campos según Elizabeth Jelin (2014, p.237). El primer campo es la consolidación del paradigma de los DD.HH. como parámetro legítimo para interpretar jurídica y socialmente las atrocidades cometidas. Un segundo campo es la no linealidad temporal de la memoria. El pasado ya no aparece como fijo y cerrado, por el contrario; lo específico de la memoria es que ésta queda abierta. Un tercer campo, dice Jelin, son las políticas de la memoria como modos de institucionalización. Cuarto campo, una perspectiva de género que enriquece los espacios de normatividad y análisis en las violaciones sexuales. Y quinto, la centralidad de la relación de parentesco; los familiares de las víctimas se encuentran en un lugar emblemático que ha jugado un rol esencial en la articulación de las demandas. "El desafío histórico reside en poder construir un compromiso cívico con el pasado que sea más democrático e inclusivo" (Jelin , 2014, p.250).

En este contexto, las formas de la memoria adquieren relevancia para la elaboración de políticas que promuevan los DD.HH. Es el debate que los 40 años del golpe militar en Chile, celebrados bajo el primer gobierno de la coalición de derecha después del regreso a la democracia, ha traído para la reflexión.

La hipótesis que guía este artículo es que la patrimonialización de la memoria tiene alto rendimiento político pues no tiene como fin la resolución del conflicto, la recompensación, la restitución de una comunidad imaginada, el perdón o el olvido. Mucho menos tiene por objetivo la comprensión científica de los hechos bajo una lógica causal (Basaure, 2014) sino, precisamente, la preservación de la herida abierta y, con ello, la reproducción constante de memorias en construcción.

Esta hipótesis deriva de tres supuestos principales. Primero, que coexisten en el imaginario social, tanto como en las políticas de Estado, distintas concepciones y tratamientos de la 
memoria. Segundo, que estas concepciones o formas de memoria dicen relación con la reducción de complejidad que las experiencias del tiempo o regímenes de historicidad producen, Koselleck (1993), Luhmann $(1976,2007)$ y Hartog (2014). Y que, por lo tanto, estas presentan diferentes rendimientos políticos según la situación histórica.

Basándonos principalmente en la descripción de los regímenes de historicidad de Hartog (2014) y la concepción de memoria como un mecanismo en construcción que realiza Stem (2012), se propone pensar que en tiempos donde la modalidad temporal dominante es el presente, la construcción política sólo es posible en base a horizontes temporales que aparecen en el presente. Esto quiere decir que la memoria no implica consolidar una visión de pasado consensuada (aunque sea moralmente) sino consolidarse a sí misma como la construcción constante de pasados y futuros presentes. Tercero, que si comprendemos la política como un espacio de aparición en donde se desarrolla la humanidad al compartir en él la pluralidad de experiencias de mundo, cualquier modo de homogenización cultural, sobre todo el totalitarismo, impide a los ciudadanos elaborar los errores del pasado y por ello acceder a la reconciliación (Arendt y Kohn, 2008).

$\mathrm{Ni}$ la indiferencia benigna que el concepto liberal de tolerancia propone, ni la esencialización del reconocimiento de identidades (y por tanto desatención a aquellas diferencias que exceden dichas identidades) de una propuesta comunitarista, permiten comprometer a otros en un discurso acerca del mundo que compartimos. La ética de la mundanidad de Hannah Arendt cobra más sentido que nunca, al sugerir que, en vez de comenzar por el reconocimiento de la verdad moral de fechorías y procediendo de eso hacia la restauración de comunidad, la reconciliación política empieza con la invocación de un nosotros que aún no es, en términos en los cuales busca darse cuenta de un entendimiento compartido de lo que fue antes memoria. Desde esta perspectiva, el nosotros que una reconciliación política debe invocar es un horizonte de posibilidades que permita una política reconciliatoria en el presente. Un horizonte riesgoso, diverso e indeterminado pero guiado por la promesa del Nunca Más (Schaap, 2005).

En este sentido, el tratamiento político más adecuado a una memoria en construcción es aquella que procura mantener el proceso constructivo vivo. Aquello implica mantener a su 
vez el riesgo que la diversidad trae consigo en la aparición de seres heterogéneos en el espacio político. Mantener el riesgo propio de la política, es mantener vivo el conflicto, o la posibilidad de conflicto respecto a la memoria del pasado. La preservación del patrimonio, a diferencia de la conservación de lo museal o la restauración del monumento, es la tarea de mantener vivo aquello socialmente marcado. La patrimonialización, se entiende hoy como aquel fenómeno en el cual se valorizan relaciones entre formas diversas (objetos físicos, rituales, lenguas, paisajes naturales, etc.) y la sociedad (Davallon, 2006), es decir, la valoración de la reproducción de un enlace (Meirovich, 2011).

Magdalena Krebs (entonces directora de la DIBAM) inició controversias con sus dichos en el diario La Tercera al poner en duda la función pedagógica del Museo (Krebs, 2015. Diario La Tercera, s. f.). Tales dichos han reabierto un debate que nos recuerda el conocido debate de historiadores en Alemania y el tratamiento que se le ha dado al Holocausto Nazi como modelo para lidiar con el terrorismo de Estado y los crímenes de lesa humanidad.

\section{Historikerstreit, el debate de historiadores sobre el Holocausto Nazi} En las primeras reflexiones en torno a los crímenes gestados por el nacional-socialismo hitleriano después de 1946, se observan dos grandes corrientes. Por un lado, la interpretación crítica, no solo hacia los hechos pasados sino a la construcción presente de una identidad post-nacional que debía incorporar el Holocausto en la memoria y la identidad alemana. Tradición liderada por el filósofo y sociólogo alemán Jürgen Habermas a partir de la década de los setenta (Jara, 2013).

Por otro lado, la culpa y la dificultad que la memoria del Holocausto implicaba para la construcción de la auto-imagen alemana y de los alemanes generó una memoria que se negaba a reducir la historia nacional a este trágico hecho. Esta tradición se estableció como una política de perdón y olvido del pasado nazi. La estrategia era relativizar el crimen conmemorando a todas las víctimas por igual, tanto aquellos que fueron exterminados en los campos como los miembros de la SS fallecidos durante la guerra (Crownshaw, 2010). El historiador Ernst Nolte llevó adelante el debate respecto a la necesidad de comprensión de la historia para el aprendizaje colectivo. Argumenta que el acto de comprender la 
historia no elimina el poder juzgar la responsabilidad de los actores, sin embargo, llama a contextualizar a Hitler y sus motivaciones (Jara, 2013). Por ello se le acusa de revisionismo e inaugura el famoso Historikerstreit. El camino a la reconciliación política que esta corriente plantea es el de comprender el contexto histórico como condición de posibilidad del crimen, para aprender de éste, para cerrar la herida y construir políticamente una Alemania en la cual se procure no llegar a condiciones de posibilidad de estas atrocidades. En simple, esta corriente entiende la Historia como Magistra Vitae, y nos dice que ahí donde hay algún tipo de crisis social es posible que se violen los derechos humanos.

Como explica Jara (2013) el mayor legado de la postura liderada por Habermas es la instauración de la necesidad de que los Estados perpetradores se responsabilicen por los hechos acaecidos y lleven a cabo acciones de reparación. Con ello se universaliza el modo de comprensión y acción de situaciones históricas similares. La universalización del Holocausto ha generado un grado de empatía tal entre sobrevivientes de la violencia de Estado que se ha convertido, sin lugar a dudas, en el eje guía en el debate de los DD.HH. y la construcción de una memoria cosmopolita (Sznaider y Levy, 2002).

Esta universalización desata algunas críticas respecto a la descontextualización del crimen particular. En el caso del Holocausto, como explica Baer (2012), esta descontextualización tiene consecuencias no anticipadas como la producción de un antisemitismo secundario que olvida el crimen al pueblo judío en pos del crimen a la humanidad completa. Con ello se excluye la memoria judía de la memoria del Holocausto dando continuidad a una antigua semántica que Baer recuerda que el diputado francés, Clermont-Tonnerre, enunciase en 1789: “A los judíos como individuos todo, como nación nada". Según Jara (2013), es posible apreciar en Chile también estas consecuencias no deseadas en un sentido diferente al de Baer pero que permiten abrirse al debate respecto a la contextualización de la atrocidad. Esto es que se debe aspirar a una memoria reflexiva y no estática, a una memoria en construcción en el presente y esto es altamente improbable cuando no se incorporan memorias irracionales, pues la memoria social es un mecanismo sistémico y no un principio normativo. 


\section{La crítica al Museo de la Memoria y los Derechos Humanos, el Historikerstreit chileno}

El Museo de la Memoria y los Derechos Humanos (MMDH), inaugurado el año 2010 en el marco de la celebración del Bicentenario de la República de Chile, tiene una misión clara que es:

Dar a conocer las violaciones sistemáticas de los derechos humanos por parte del Estado de Chile entre los años 1973-1990, para que a través de la reflexión ética sobre la memoria, la solidaridad y la importancia de los derechos humanos, se fortalezca la voluntad nacional para que Nunca Más se repitan hechos que afecten la dignidad del ser humano («Definiciones Estratégicas www.museodelamemoria.cl», s. f.).

En el mismo sitio web institucional se expone en el apartado Visión del Museo, que este pretende ser "un espacio que contribuya a que la cultura de los derechos humanos y de los valores democráticos se conviertan en el fundamento ético compartido", además que de identificarse como:

Un proyecto de reparación moral a las víctimas y propone una reflexión que trascienda lo sucedido en el pasado y que sirva a las nuevas generaciones para construir un futuro mejor de respeto irrestricto a la vida y la dignidad de las personas («Definiciones Estratégicas www.museodelamemoria.cl », s. f.).

Lo que según Basaure puede expresarse sintéticamente en la siguiente fórmula: exponer $X$ (violaciones de los derechos humanos 1973-1990) para generar $Y$ (procesos específicos y profundos de reflexión), que sean la base de $Z$ (una voluntad nacional, basada en un fundamento ético compartido, para que $X$ Nunca Más tenga lugar) = "Exponerdocumentadamente- $X$ para un Nunca-Más- $X^{\prime \prime}$ (Basaure, 2014, p.173).

Varios historiadores, a través de los medios de comunicación de masas, han planteado críticas respecto de la ausencia de documentación previa al Golpe militar. El historiador, Francisco González, citado por Basaure (2014) ha señalado que el MMDH plantearía "(...) 
una visión sesgada de la historia, sin mirarla en su conjunto (...) La historia no la podemos parcelar sin dar cuenta del contexto y sus causas". Magdalena Krebs, como ya hemos mencionado, inició la controversia con una carta al director publicada en un medio de derecha. Acusa en su carta al diario El Mercurio, al MMDH de ofrecer una "visión incompleta de los hechos" ocurridos en Chile y de "circunscribir su misión sólo a las violaciones a los DD.HH., sin proporcionar al visitante los antecedentes que las generaron", concluyendo que "sería una gran contribución que el museo explicara los hechos anteriores al golpe" (El Observatodo, 23-06-2012).

Esta crítica es reducida por Basaure a la fórmula A (antecedente-contexto) X (violación de los $\mathrm{DDHH}$ ) y afirma que estas fórmulas son lógicamente incompatibles, plantean no sólo un punto de base diferente sino, una diferente comprensión de la temporalidad, como veremos en más detalle. La Historia como Magistra Vitae no es funcional a la reconciliación política ni a la construcción comunitaria con base en el horizonte temporal futuro. Para ello, no es necesario erradicar la exposición y documentación exhaustiva de los hechos históricos, esta puede realizarse en otros espacios para los que sí sea relevante. Desde una mirada decimonónica del Museo Histórico Nacional aparece como un espacio que permite una documentación previa a la catástrofe, pero ¿es realmente posible sostener la condena a la violación de los DD.HH. bajo esta fórmula?

Basaure explica que hay tres tipos de dificultades; una de carácter lógico-moral, una teórico-social y otra filosófico-histórica, respecto a la posibilidad de incorporar una alternativa del tipo propuesto por Krebs:

i) La fórmula pedagógica de contextualización, presenta una dificultad lógico-moral al no poder desligarse de una justificación indirecta de la violación de los DDHH. La posición de los detractores del MDDHH -que aquí es considerada como adecuada a un diálogo racional y público - queda bien resumido en las palabras ya citadas de Magdalena Krebs cuando señala el error que implicaría el "circunscribir su misión sólo a las violaciones a los 
DD.HH., sin proporcionar al visitante los antecedentes que las generaron". (Basaure, 2014, p.190).

ii) Una dificultad en el ámbito teórico social y político. La fórmula pedagógica de la contextualización subordina el valor de los DD.HH. al valor del orden institucional. Como explica Basaure:

Para esta estrategia se debe contribuir a la construcción de una cultura política según la que aquello que debe ser evitado, en primer lugar y a toda costa, son las situaciones de conflicto y quiebre social e institucional, pues de ese modo se podría evitar la violación de los derechos humanos. En la medida que en la mentalidad ciudadana se logre incorporar férreamente el valor del orden institucional — de acuerdo a la lógica interna de la fórmula de la contextualización—, en esa misma medida se estará evitando aquél antecedente que históricamente habría generado situaciones de violación a los derechos humanos (Basaure, 2014, p.191).

No es el hecho histórico, en este caso de quiebre institucional, lo que permite afirmar los valores de respeto a los DD.HH., bajo la fórmula de Krebs o de la crítica sobre el tratamiento de la memoria que realiza la derecha chilena, el Nunca Más fundante queda instalado en el conflicto social y quiebre del orden y no en la deshumanización y el crimen. Y ello, una vez más, evidencia una lógica temporal anticuada que busca restituir una unidad nacional que es imaginada, que nunca existió. Y, como dice Basaure, una apología al orden que no asume como parte constitutiva de la construcción política el conflicto. El conflicto o como Carl Schmitt (2005) define "la siempre presente posibilidad de la relación amigoenemigo" es necesario en la política. 
iii) Es en el ámbito de la filosofía de la historia que la formula pedagógica encuentra su tercera dificultad, pues no existe ninguna necesidad histórico-causal entre el hecho A y el $\mathrm{X}$. "Simplemente no es posible ver por qué de un clima de beligerancia y quiebre institucional debiesen seguirse estas atrocidades" (Basaure, 2014, p.193), además supondría la irreflexiva repetición de la historia desestimando los cambios y transformaciones que la sociedad ha tenido.

Como argumenta Basaure entonces, en contraste con la fórmula pedagógica de la contextualización, "la posición oficial del MMDH no se ve enfrentada a ninguna de las dificultades señaladas arriba, y ello gracias a la propia estructura lógica de su fórmula" (Basaure, 2014, p.194).

La patrimonialización de la memoria sobre la violación a los derechos humanos perpetrados por el Estado de Chile hacia sus propios ciudadanos, tiene el potencial rendimiento político de preservar la memoria en construcción de manera tal que Chile pueda instaurar (y no restaurar) aquella cohesión social que necesita para su democracia.

La patrimonialización juega un rol preponderante en esto, a diferencia de estrategias como el olvido (mirar hacia el futuro), el recordar para olvidar (la simple catarsis del testigo o el confeso) y la monumentalización de héroes del conflicto.

Algunos profesionales de área de los Estudios Patrimoniales, han planteado como un desafío superar la extraña relación que estos espacios de memoria patrimonializada mantienen con la museología. El patrimonio, ha superado en su capacidad vinculante a la monumentalización y a la musealización. Mejor dicho, aparece como una estrategia política para la construcción de comunidad, más adecuada a un régimen presentista de historicidad. Con ello ha desplazado al museólogo de su rol protagonista (Alegría, 2013) relevando a la comunidad. En el MMDH la estrategia se diseña y/o ejecuta inter-disciplinariamente, pero su finalidad es absolutamente política. Tal como lo expresa la presidenta Michelle Bachelet en el discurso inaugural del MMDH el 11 de enero del 2010: "Este museo es un espacio 
para la construcción de las memorias en Chile... Por ello, parte de la fortaleza de este espacio, es que considere la diversidad de las memorias presentes en Chile" (Bachelet, 2010).

\section{Del concepto de memoria como mecanismo de articulación temporal presentista}

El tiempo que marca el reloj nos permite distinguir secuencias entre antes y después, donde sólo existe futuro y pasado. En la teoría de sistemas de Luhmann (1976, 2007) se identifica conceptualmente el tiempo como el proceso que permite la emergencia de una forma (Ramos Torre, 1992). Esto es, una distinción con el entorno en la que simultáneamente emerge una distinción entre antes y después, que comúnmente asimilamos como tiempo cronológico. En simple, cada vez que se observa e identifica algo, en el actuar hay una operación temporal, un antes donde lo observable estaba indiferenciado y un después donde algo se distingue. Con esta operación podemos observar el cambio y el flujo en secuencias de eventos. Es en esta secuencialidad que emerge el sentido como medio por el cual se auto-constituye la identidad. Con la observación de la secuencia de eventos antes/después, un sistema genera una nueva distinción, experimenta la continuidad y con ello puede extender el presente de manera no temporal y construir su historia. Para que un sistema pueda construir su identidad necesita entonces distinguir entre la actualidad de sus operaciones y sus horizontes de posibilidad.

Estos horizontes son el pasado y futuro, que permiten que se dé simultáneamente lo simultáneo (que la potencialidad y la actualidad se dan a la vez al momento de la selección) y lo no simultáneo de la distinción misma. De este mecanismo resulta una complejidad ordenada, aparece organizada previamente por la memoria selectiva que permite no sólo la actualización (o no) de un elemento o una relación entre elementos, sino la construcción de un tiempo histórico, una temporalidad como distingue conceptualmente Barbara Adam (1990, p.9-47) de un tiempo cronológico. 
La temporalidad, como articulación presente de los horizontes temporales es resuelta, según el sociólogo Pedro Güell de maneras diversas y a través de múltiples mecanismos en cada sociedad:

Uno de ellos es la construcción de sentidos de continuidad temporal mediante símbolos, rituales y narraciones. Son elaboraciones acerca del sentido simbólico del transcurso del tiempo que contribuyen a articular las biografías individuales con el orden social, el cambio de la sociedad con la pertenencia de los individuos a algo fijo, los sacrificios del presente con las plenitudes del futuro" (Güell, 2009, p.17).

Hartog, en su más reciente libro Creer en la Historia (2014), dice que podemos observar hoy un cambio de régimen de historicidad. Un régimen de historicidad es el modo particular en que se articulan las tres categorías temporales que organizan la experiencia del tiempo: pasado-presente-futuro. Es la manera de construir el tiempo que tiene cada sociedad según sea la preponderancia de una de estas categorías por sobre las otras. Hasta el siglo XVIII, indica el autor francés, la sociedad mira hacia el pasado para darse sentido, en el siglo XIX y XX domina el futuro con la idea de progreso, por ejemplo. En la actualidad la inmediatez de las relaciones de mercados, de los medios de comunicación y de las redes sociales evidencian que estamos experimentando un nuevo régimen de historicidad y por lo tanto entrando a una nueva época histórica. El ecologismo y la patrimonialización son ejemplos de este nuevo modo de articular temporalidad, donde el futuro no es la meta que debemos alcanzar con rapidez (al modo futurista del progreso) sino que el foco está en un presente que debemos preservar ante la amenaza del futuro.

Sin pararse en el mismo piso epistemológico ni disciplinar, Hartog y Luhmann coinciden en el carácter co-constitutivo que la articulación de temporalidad y la complejidad de la sociedad. La modernidad entonces emerge y articula simultáneamente una experiencia del tiempo que va más allá de la ruptura con un pasado como puede entenderse comúnmente lo moderno y, basándose en Koselleck, afirman que el tiempo moderno es el presente. 
El presente se vuelve la forma suprema de temporalidad (Mead en Flaherty, 2001) y con ello la Historia con mayúscula (Hartog, 2014) ha perdido su eficacia como acceso verídico al pasado, ya no es creíble. El concepto moderno de Historia que miraba el pasado a la luz del futuro ha sido sucedido por el concepto de memoria, que observa el pasado a la luz del presente, "Clío fue sucedida por su madre, Mnemosine" (Hartog, 2014, p.37).

Para Marcel Gauchet, el cambio de relación con la historia:

Tomó la forma de una crisis del porvenir de la cual el desvanecimiento de la idea revolucionaria no fue más que el síntoma más vistoso. Con la posibilidad de representarse el porvenir, lo que entra en crisis, es la capacidad del pensamiento de la historia de volver inteligible la naturaleza de nuestras sociedades sobre la base del análisis de su devenir y su capacidad para proporcionarles guías para su acción transformadora sobre ellas mismas, en virtud de la previsión y del proyecto (Gauchet en Hartog, 2014, p.37).

Con el paso del régimen de historicidad futurista asociado al concepto moderno tradicional de Historia, emergen nuevos conceptos que se vuelven consignas, prácticas y se traducen en políticas: memoria, patrimonio e identidad, en el caso que nos convoca.

Durante siglos, gobernó todo el registro de la historia como maestra de ejemplos, exitosos o no, de acción. Al igual que Luhmann y Koselleck, Hartog utiliza la idea de horizonte temporal (aquella línea que parece separar el cielo de la tierra y que se aleja a medida que uno se acerca) y explica que es en la brecha entre el horizonte de espera y el campo de experiencia que se teje el tiempo histórico.

Hartog nos interroga entonces: si es cierto (o posible) que el tiempo del mundo actual es el presentismo del instante, ¿cuál puede ser su eficacia para la acción en curso, su capacidad 
para describir adecuadamente, para hacer comprender y para prever? Por ello, plantea en su hipótesis, que es posible observar un ascenso de la memoria. Ante un régimen presentista, la dupla del juez y el historiador se hace insuficiente, se requiere de un tercer miembro: el testigo.

Una reflexión similar hace Alejandro Fielbaum, en Submemorias del desarrollo, literatura y memoria en la ensayística de Silviano Santiago (Fielbaum, 2014, p.75), respecto al rendimiento de la memoria literaria que permite 'desenterrar y resucitar' paisajes, cadáveres, recuerdos. La literatura, explica el autor, permite trabajar una experiencia con la que no se puede dar, un nombre sin referente. El narrador posmoderno se despreocupa por la 'veracidad' del relato cuando la experiencia que se debe recordar es la de quien no puede dejar su recuerdo. Por ello, nos dice Hartog (2014) el auge de las historias, micro historias o relatos biográficos en la investigación social, por sobre esa Historia con mayúscula que pretende constituirse como verdad científica. Se desplaza la credibilidad de la prueba objetual de un hecho al subjetivo testimonio.

El cambio de época en relación al régimen temporal que experimentamos, que Hartog nos pretende mostrar y que coincide con otros autores ya citados, no es en la forma en que es tratada la memoria sino en el elemento que en dicha articulación prevalece. Este ya no es el pasado (glorioso o vergonzoso) ni el futuro (como progreso o catástrofe), sino el presente como espacio único de construcción.

Cabe preguntarse por cómo el régimen de historicidad o la temporalidad que experimentamos/desarrollamos determina la forma de construcción de una comunidad política, nacional, continental o regional, sin importar su extensión. "La extensión no temporal del tiempo constituye horizontes temporales para la conducta selectiva, es decir; un pasado que nunca se puede reproducir y un futuro que nunca puede empezar" (Ramos Torre, 1992, p.177). El pasado y el futuro sirven para la construcción de identidad presente. Memoria es la convocación de ambos horizontes temporales en el presente. En ese sentido el pasado no se puede reproducir pero tampoco dar por terminado, aparece en el presente 
como inacabado, como una herida abierta, de manera tal que "los que tienen memoria, son capaces de vivir en el frágil tiempo presente. Los que no la tienen no viven en ninguna parte" (Guzmán, 2010).

El historiador Steve Stern (2012), explica que es posible observar una segunda complejidad en la forma de experimentación del tiempo en nuestro continente. Esto, porque ella no es lineal; en el desplazamiento de una etapa por otra, estas se traslapan. La construcción de memoria en el Chile democrático se ha realizado, según Stern, en tres etapas traslapadas. La primera etapa requería reconocimiento y documentación de la Verdad. La segunda, la aplicación de formas de Justicia, sean castigos o retribución a víctimas. Y en una última etapa, la que vivenciamos hoy, la construcción de memoria requiere de materialización física y renovación de sentido para las nuevas generaciones (que ya no son testigos directos).

Marca dicha primera etapa entre 1989 y 1993 donde destaca la labor de la Comisión Rettig en la investigación de los hechos junto con la pequeña apertura hacia la justicia que permite el primer presidente de la transición, Patricio Aylwin, al limitar la aplicación de amnistía. Sin embargo, tal como el autor lo comenta, esta fue una pequeña puerta que se vio trabada por el conocido boinazo ${ }^{1}$ de 1993 (Stern, 2012, p. 108).

Una segunda etapa marcada por Stern es la comprendida entre 1992 y 2006. Etapa de diversos ciclos, altos y bajos en una sinergia conflictiva entre actores. La sinergia casi dormida de finales del gobierno de Aylwin reflota en eventos como la Mesa de Diálogo y la Comisión Valech y se consolida, según Stern, con la elección de Michelle Bachelet en 2006. El autor sugiere que la valoración negativa de los hechos ocurridos se consolida para una mayoría de la sociedad civil y del Estado. Por lo tanto una nueva concepción de memoria surge y es, a diferencia de la anterior que se caracteriza como una lucha por la

\footnotetext{
${ }^{1}$ Evento ocurrido el 28 de mayo de 1993, durante el gobierno de Patricio Aylwin, donde soldados del Ejército de Chile (aun comandados por Augusto Pinochet) se reunieron en el Palacio de la Moneda con indumentaria de combate (boinas negras) para apoyar al dictador y su hijo ante la acusación de corrupción conocida como "Pinocheques".
} 
hegemonía de la historia oficial (una lucha por los criterios de selección por decirlo de manera sistémica), la relevancia de asumir responsabilidades por una tragedia nacional compartida (Stern, 2012, p. 109).

La forma heroica de producir historia queda atrás. Frente a la tragedia, el Ejército se ve imposibilitado de emitir su historia oficial de salvación de un país en crisis institucional como justificación de la masiva violación de derechos que la Comisión Valech y otras organizaciones ya habían demostrado y estabilizado como verdad. Sin embargo, argumenta Stern, y es lo que nos interesa para nuestra hipótesis, aquí no se logra cerrar la caja de la memoria.

\section{Patrimonialización de la memoria, la conservación de la herida abierta para una política de Nunca Más}

Si seguimos los argumentos anteriores, podemos comprender que la necesidad de políticas de memoria tiene relación con la necesidad presente de elaborar el pasado tanto como de domesticar la incertidumbre del futuro. Esto debido a que la búsqueda de Verdad y Justicia es tan apremiante como la incerteza de que hechos como estos vuelvan a pasar. El futuro aparece en el presente como advertencia que obliga a normar una vida en común presente. "El Estado tiene la obligación de promover la memoria sobre dichos hechos con el fin de dignificar y honrar a quienes fueron injustamente violentados, todo con el objetivo último de evitar su ocurrencia en el futuro" (Fríes en Bustamante, 2014, p.17). En la construcción presente de cohesión política, como veremos, aparece un relativo consenso respecto a que el recordar para nunca olvidar, como política de memoria es, el único modo en que los ciudadanos violentados y traumados por parte de uno o más Estados logren retomar la confianza en él de manera de participar de una comunidad política, como expone Assmann (2010).

La promesa del 'Nunca Más' es el espíritu de la ética universal de la que Arendt nos hablaba en su análisis al juicio de Adolf Eichmann y las promesas de la política (2003; 
2008) con tanta claridad. Para Arendt lo dramático, no es la crueldad de la violencia ejercida por el Estado sino de aquello que involucra un ataque a la diversidad humana como tal, un intento de eliminar la pluralidad que inevitablemente emerge cuando los seres humanos se unen para actuar y hablar sobre el mundo en común que comparten (Arendt, 2003, 9-268). La reconciliación política empieza con la invocación de un nosotros que aún no es, en términos en los cuales busca darse cuenta de un entendimiento compartido de lo que fue antes, una memoria común fundada en la promesa futura.

Por un lado, se debe poder confiar en la nueva ética fundante basada en la valoración moral negativa de la violencia. Por otro, la confianza permite reducir la complejidad de un futuro que advierte los peligros de la acción presente. Como dice Norbert Lechner, la confianza "no elimina la incertidumbre pero permite tolerar un mayor grado de inseguridad" (Lechner and Moulian, 2007, p.392) y de hecho, la confianza, en un horizonte de posibilidad que jamás se alcanza, constituye más bien una apuesta desesperada que una certeza.

La política gira en torno a los términos de asociación y disociación de las personas. Tal como rescata Andrew Schaap en su libro Political Reconciliation (2005), la política es la forma de interacción humana orientada al disenso y no al consenso y, citando a Schmitt (1996, p.53), afirma que el mundo político es un "pluriverso no un universo".

Es decir que para pensar políticas que permitan integración social en Chile tras los traumáticos hechos vividos en dictadura debiésemos enfocar esfuerzos en, precisamente, la preservación del conflicto que permite evidenciar cognitiva y moralmente la irrelevancia total de la Historia como ciencia en la búsqueda de causas a la tragedia. Es decir, Mnemosine, la musa de la memoria, se superpone a Clío, la musa de la Historia.

Sin embargo, estas musas no se entregan el 'testigo' cual carrera de posta, no se entregan la una a la otra el dominio sobre la historicidad que los seres humanos y la sociedad experimenta. Más bien, podemos asegurar que en el debate que aquí comentamos se evidencia la forma traslapada de sus momentos de emergencia. 
Observar la memoria así nos permite una nueva separación, si ya la Historia con mayúscula en términos de Hartog se separa de la memoria, pues es necesario hacer una nueva y más fina distinción entre historias (con minúscula) y memoria. Memoria no constituye todo recuerdo, al referirnos a memoria no nos referimos entonces a todo relato sobre el golpe de Estado y dictadura, sino a la articulación del pasado y futuro en un presente que funda una ética común para la construcción social. Construcción que, como ya hemos argumentado, mantiene el conflicto (o la herida) vivo pero limitado en su actuar por la promesa futura.

Stern argumenta que a partir de la transición a la democracia la memoria produce una sinergia conflictiva entre actores. Es decir que entre la sociedad civil y el Estado existe una interdependencia para lograr un avance en materia de DD.HH. y que esa interdependencia pasa por periodos de mayor o menor conflicto. Se requiere una alta demanda de la sociedad civil para que un Estado incorpore un tema desatendido en su cronograma y, a su vez, se requiere del Estado para llevar a cabo una agenda. En sus palabras "las sinergias entre Estado y sociedad, necesarias pero también conflictivas, que surgen a partir de una transición democrática también significan una construcción de la memoria” (Stern, 2012, p. $105)$.

\section{Del monumento moderno al patrimonio post-moderno}

En este contexto, Stern identifica formas de materialización físico-institucional como la instauración de lugares que sirvan a la formación cívico-pedagógica para las nuevas generaciones que no tienen en su memoria personal la tragedia. Si bien en su gran mayoría esta fórmula de tratamiento cívico-pedagógica requiere de una materialización, desde el punto de vista de los estudios patrimoniales, no es en su materialización sino más bien su calidad de objeto (material o inmaterial) de protección.

En esta materialización encontramos nociones que, una vez más, es importante distinguir entre sí, pues lo que hoy en museología denominamos proceso de patrimonialización, no es un concepto unívoco. Hartog (2014, p.68) reconoce la plurivocidad de la noción, pues el 
patrimonio ha surgido entre la historia y la memoria. Ello nos obliga a preguntarnos ¿cuándo algo se patrimonializa y para qué patrimonializamos como sociedad?

Hoy no definimos qué es patrimonio desde las características propias y auténticas de un objeto, sino desde la función que cumple para la sociedad el patrimonializar. Queremos decir con esto que el patrimonio es lo patrimonializado; no 'andan' patrimonios culturales por ahí esperando ser descubiertos como comúnmente ocurre cuando la élite de expertos le indica a una comunidad que lo que posee es valioso y que el no valorarlo lo pone en riesgo. El patrimonio emerge en la patrimonialización que, como expondremos aquí, es un mecanismo que le permite a la sociedad asumir la complejidad que implica la continuidad identitaria en presentes que duran poco. En ese sentido, los mecanismos de patrimonialización están intrínsecamente unidos a los modos de temporalidad que se coconstituyen con la sociedad misma.

Las primeras formas de coleccionismo que dan origen al Museion, el templo de las Musas, se erige como un centro con carácter pedagógico para la cultura y las artes, aunque aún cargado de religiosidad. El Museion es aquel espacio donde:

Sólo ellas (las musas) pueden soplar al oído de los hombres su dominio total sobre lugares, nombres, hechos, cosas; ellas son las que ponen orden en el barullo de los conocimientos, las únicas que pueden enseñar a los hombres del saber del arte de la enumeración metódica y atravesar las fronteras del tiempo y el espacio, dándoles a conocer cosas antiguas en el tiempo y lejanas en el espacio. (Ballart Hernández y Juan Tresserras, 2001, p.12)

Los primeros museos/templos, contaban con sacerdotes que actuaban como guardianes hasta después del edicto de Milán (313 d.e.c.) cuando el cristianismo se expande por el Imperio Romano y comienzan dos procesos clave. Por un lado, el uso de la representación 
pictórica, escultórica y arquitectónica para la evangelización y, por otro, el atesoramiento de reliquias. Algo que es superado en coexistencia, como ya hemos argumentado, por la construcción del proyecto de Estado-Nación moderno.

Aunque es sencillo evidenciar la coexistencia de estas lógicas tanto en la producción museológica como en la percepción del público ${ }^{2}$, el vínculo del sujeto con los objetos que las visiones religiosas y nacionalistas (heroicas) traen, son ya obsoletas para entender el patrimonio.

Explica Pierre Nora (2009), que el fenómeno del patrimonio cultural ha desplazado a los museos. Según Nora, “fue ese silencioso trabajo de recomposición, de una asombrosa rapidez, el que aseguró el éxito del año del Patrimonio; merece ser recordado puesto que fue ese año que la palabra misma hizo su revolución semántica” (p.184). El patrimonio se manifiesta mucho más complejo, dinámico y fructífero que el museo, que pretende contenerlo o articularlo, incluso en sus modalidades más participativas, "salió de los museos nacionales para invadir los espacios verdes o afirmarse en las piedras de las viejas calles" (Nora, 2009, p.185).

La patrimonialización, como proclamación y preservación del porvenir se vuelve operatoria tanto para el pasado como para el futuro. Por ello, es un concepto que pretende dar cuenta (y a su vez un mecanismo que pretende dar solución) a una nueva relación con el tiempo. De un modo similar, el ex secretario general del Consejo de Monumentos Nacionales $(\mathrm{CMN})$, José de Nordenflycht explica que:

La memoria y su gestión, en base a sus dos sentidos más evidentes: máquina en el sentido aristotélico de mecanismo y motor inicial, pero también máquina en el sentido

\footnotetext{
${ }^{2}$ En el Museo Histórico Nacional de Chile es posible hilar la continuidad de discurso de los visitantes en los libros de visita desde su creación hasta hoy. Por ejemplo, la firma de Carmela Carvajal, viuda Arturo Prat, quien escribe en el libro de visitas del antiguo Museo Militar (1903), el sobrecogimiento que la envuelve al estar frente a la alegoría, Prat guiado al sacrificio por el genio de la Patria, de Cosme San Martín ( ${ }^{\circ}$ Cat.3948). Aun podemos encontrar citas similares en los libros de visita actuales del Museo Histórico Nacional de Chile en referencia a objetos de la historia reciente, como los lentes del ex presidente Salvador Allende, sobrevivientes al bombardeo.
} 
político coloquial de conjura. Ambos sentidos aluden a los principios causales que articulan la necesidad de construcción de una historiografía artística, la que hacia fines del siglo XIX converge como insumo para la construcción del estado nacional moderno, por lo que no es casual que historiadores como Aloïs Riegl se refieran a esto como el culto moderno a los monumentos (Nordenflycht n.d., p.1, énfasis original).

La conservación y restauración como devolución de valores rememorativos y de contemporaneidad (Riegl, 1987, p.9) son políticamente disfuncionales, producen una temporalidad de identidad modernas. El patrimonio, a diferencia del monumento no se restaura, se preserva. ¿Qué quiere decir esto? La acción efectiva de intervención no es hacia un objeto del pasado que corre peligro de perder un valor que le es ontológicamente propio, es la restauración. Y la restauración de una unidad perdida en términos de comunidad política es imposible, como ya vimos. Indica Schaap (2005) que la restauración de comunidad para una reconciliación política empieza con la invocación de un nosotros que aún no es o mejor dicho es un horizonte de posibilidades en el presente.

La memoria monumentalizada ha sido efectiva para la reparación simbólica de los daños provocados a quienes se vieron vulnerados de sus derechos por parte del Estado. Sin embargo, tiene una carencia y es que eterniza una construcción de memoria, por lo que pierde rendimiento en torno a la construcción de una comunidad política futura, deja de ser una memoria en construcción. Es por ello que la patrimonialización, a diferencia de la musealización o monumentalización que son sin duda parte del repertorio de tratamientos posibles de la memoria, se posiciona como aquella capaz de mantener la construcción de memoria viva.

Llorenç Prats acuña el término de patrimonios incómodos cuando refiere a "repertorios patrimoniales políticamente incorrectos o actualmente indeseables, a pesar de que cumplan todos los requisitos de legitimación para su puesta en valor y activación" (Prats, 2005, p.26). Otros intelectuales invitan a utilizar el término de patrimonio negativo cuando se 
patrimonializa una memoria con valor moral negativo. Sin embargo, tanto la memoria como la patrimonialización de ésta, emergen indistintamente del cómo sean moralmente valoradas, su objetivo es dar sentido y cohesión, permitir la construcción de identidad colectiva donde la continuidad no es posible.

Citando a Young, Richard concibe la función de las políticas de patrimonialización de la memoria como una retórica del anti-monumento, es decir, el "fisurar las significaciones homogéneas del pasado" (Richard, 2010, p.235). Las formas de patrimonialización de centros de tortura, de testimonios, permiten descongelar y preservar recuerdos y con ellos abrir a la reflexión crítica constante, a la constante construcción de memoria. Aunque estos muchas veces se mezclan en un sólo espacio. El ex cuartel de la DINA conocido (por su ubicación en la ciudad de Santiago) como Londres 38, se concentra en ésta tarea, sin embargo en otras patrimonializaciones, como el MMDH o el Parque por la Paz Villa Grimaldi, podemos encontrar también la monumentalización como estrategia conviviendo con otras. Tal es el caso ejemplar de la fundación Yad Vashem en Jerusalén. En éste espacio confluyen múltiples estrategias que resuelven o pretenden resolver una diversidad de problemáticas que perviven en la memoria del pueblo judío tras su deliberado exterminio (junto con el de otros millones de personas) durante la segunda guerra mundial en la Alemania Nazi.

La diversidad de estrategias responde a las etapas que la superación de un trauma tendría, incluida la imposibilidad de superarlo. Según Natasha Goldman (2006), una estrategia múltiple parece adecuada pues lo contrario implicaría que una nación es capaz de articular sus traumas de manera no problemática lo que es política y psicológicamente imposible, al menos improbable. Si bien Goldman más bien analiza la relación entre la estrategia de superación del trauma y la forma estética del memorial resultante, es interesante rescatar que, una vez más, es observable la sustitución de Clío por Mnemosine en una nueva era post-heroica. Si bien los primeros memoriales se centraron en los héroes del Holocausto (partisanos y soldados judíos, además de civiles no judíos que ayudaron a salvar vidas durante la guerra), hoy los memoriales apuntan a la ausencia y la desorientación, entre otros 
conceptos asociados a la percepción subjetiva pero validados como veraces, tan veraces como los hechos concretos. El paso de una historia heroica a una memoria reflexiva y en construcción, permitiría, según la autora, dar lugar a la auto-reflexión en torno a la vida humana y a su ausencia. Con ello incluso, a la revisión reflexiva de la ideología sionista (que no puede ser rememorada congelándose en sus inicios sin incorporar el desarrollo que ésta ha tenido), a las complejidades que vive el pueblo judío hoy en Israel y en la diáspora. Así es que el último memorial realizado en Yad Vashem, por el arquitecto Moshe Safdie, está dedicado a los sobrevivientes y a aquellos que participamos de dicha memoria en construcción.

\section{Consideraciones finales}

La instalación de la patrimonialización de la memoria en la agenda política sobre los Derechos Humanos tiene importantes rendimientos en la construcción de una comunidad nacional (e internacional) futura. Su valor pedagógico se instala más allá de sus colecciones, memoriales, monumentos y discursos, en el hecho político de su existencia.

La experiencia del Holocausto Nazi y su tratamiento político es sin lugar a dudas un ejemplo clave para pensar nuestras historias recientes en Latinoamérica, esto, debido a la universalización del crimen y de la solución política de una ética común de Nunca más. Las críticas de los múltiples sectores políticos al $\mathrm{MMDH}$ como materialización físicoinstitucional de ésta política de Nunca Más refuerzan la hipótesis de que la memoria en conflicto, la pluriversidad en la aparición política y la herida abierta es aquello a lo que se busca dar continuidad.

Como investigadores sociales o como trabajadores del patrimonio, debemos comprender la patrimonialización, lejos de ser simplemente una moda, como una contemporánea herramienta para la construcción política, la cual, así como la monumentalidad sirvió al Estado-nación, esté a favor de la constitución de una comunidad política universal plasmada en el horizonte. 


\section{Bibliografía}

Alegría, L. (2013). Saber museológico y pensamiento crítico: ¿el giro subalterno? Cuadernos de Trabajo Educativo. Corporación Parque por la Paz Villa Grimaldi, VII.

Arendt, H. (2003). Eichmann en Jerusalén. (C. Ribalta, Trad.). Barcelona: Lumen.

Arendt, H., y Kohn, J. (2008). La promesa de la política. Barcelona: Paidós.

Assmann, A. (2010). En H. G. Da Silva (Ed.), Conflict, Memory Transfers and the

Reshaping of Europe. Newcastle upon Tyne: Cambridge Scholars Publishing. Recuperado a partir de http://public.eblib.com/choice/publicfullrecord.aspx?p=1080850

Bachelet, M. (2010, enero). Discurso de la presidenta Michelle Bachelet en la inauguración del Museo de la Memoria y los Derechos Humanos de Chile. Presentado en Inauguración, Museo de la Memoria y los Derechos Humanos. Santiago de Chile.

Baer, Alejandro. (2012). Memoria de Auschwitz y antisemitismo secundario... y tres tesis sobre el prejuicio anti-judío en la España actual. Constelaciones - Revista de Teoría Crítica, (4).

Ballart Hernández, J., y Juan i Tresserras, J. (2001). Gestión del patrimonio cultural. Barcelona: Editorial Ariel.

Basaure, Mauro. (2014). Aprender críticamente de la historia. De la posibilidad de un diálogo al interior de la controversia en torno al Museo de la Memoria y los Derechos Humanos. En Bustamante, G. (2014). La agonía de la convivencia: violencia política, historia y memoria. (A. Estefane y P. y M.: D. y P. R. Conferencia Historia, Eds.).

Benjamín, W., Weikert, A. E., y Echeverría, B. (2003). La obra de arte en la época de su reproductibilidad técnica (URTEXT). México, D.F.: Itaca.

Bolaños, M. (Ed.). (2002). La Memoria del mundo: cien años de museología, 1900-2000 (1. ed). Gijón (Asturias): Ediciones Trea.

Bustamante, G. (2014). La agonía de la convivencia: violencia política, historia y memoria. (A. Estefane y P. y M.: D. y P. R. Conferencia Historia, Eds.). 
Collins, C. (2013). Las políticas de la memoria en Chile: desde Pinochet a Bachelet (1. ed). Santiago, Chile: Ediciones Universidad Diego Portales.

Connerton, P. (2008). Seven types of forgetting. Memory Studies, 1 (1), 59-71. http://doi.org/10.1177/1750698007083889

Crownshaw, R. (2010). The Afterlife of Holocaust Memory in Contemporary Literature and Culture. Basingstoke, Hampshire: Palgrave Macmillan.

Davallon, J. (2006). Le don du patrimoine: une approche communicationnelle de la patrimonialisation. Paris: Lavoisier : Hermès science.

Fielbaum, A. Submemorias del desarrollo. Literatura y memoria en la ensayística de Silviano Santiago. En Bustamante, G. (2014). La agonía de la convivencia: violencia política, historia y memoria. (A. Estefane y P. y M.: D. y P. R. Conferencia Historia, Eds.).

Goldman, N. (2006). Israeli Holocaust Memorial Strategies at Yad Vashem: From Silence to Recognition. Art Journal, 65 (2).

Guzmán, P. (2010). Nostalgia de la luz [35mm color]. Documental, Cronomedia Producciones (Chile), Atacama Producciones (Francia y Blinker Filmproduktion y WDR (Alemania).

Hartog, F. (2014). Creer en la Historia. Santiago, Chile: Ediciones Universidad Finis Terrae.

Horestein, M., y Silber, D. (2011, marzo 25). Día de la Memoria, la Verdad y la Justicia: No es una suma de casualidades. Diario Clarín.

Jara, D. (2013). El debate de los historiadores y el uso reflexivo de la historia. Revista Observatorio Cultural, (17). Recuperado a partir de http://www.observatoriocultural.gob.cl/revista/2-articulo-1/17-el-debate-de-loshistoriadores-y-el-uso-reflexivo-de-la-historia/ 
Jelin, E. (2014). El cambio de siglo en el campo de las memorias: nuevos y viejos desafíos. En Bustamante, G. (2014). La agonía de la convivencia: violencia política, historia y memoria. (A. Estefane y P. y M.: D. y P. R. Conferencia Historia, Eds.).

Koselleck, R., y Smilg, N. (1993). Futuro pasado: para una semántica de los tiempos históricos. Barcelona: Paidós.

Lechner, N. (1983, diciembre). Los DD.HH. como categoría política. Documento de Trabajo N²01 Programa FLACSO- STGO de Chile.

Lechner, N., y Moulian, T. (2007). Obras escogidas. 2: [...] (1.ed). Santiago, Chile: LOM Ediciones.

Luhmann, N. (1976). The Future Cannot Begin: Temporal Structures in Modern Society. Social Research, 43 (1), 130-152.

Luhmann, N., y Torres Nafarrate, J. (2007). La sociedad de la sociedad (1.ed. en español). México: Herder [u.a.].

Krebs, M. (2015) «El Museo de la Memoria puede mejorar su calidad pedagógica»| Cultura\&Entretención | La Tercera Edición Impresa. (s. f.). Recuperado 28 de mayo de 2015, a partir de http://diario.latercera.com/2012/07/12/01/contenido/culturaentretencion/30-113612-9-magdalena-krebs-el-museo--de-la-memoria-puede-mejorar-sucalidad-pedagogica.shtml

Meirovich, S. (2011). Preservación dinámica: la protección del patrimonio cultural inmaterial como intervención social (Tesis para optar al grado de Magíster en Trabajo Social). Pontificia Universidad Católica de Chile, Santiago de Chile.

Museo de la Memoria y los Derechos Humanos. (s. f.). Definiciones Estratégicas | Recuperado 9 de junio de 2015, a partir de http://www.museodelamemoria.cl/elmuseo/sobre-el-museo/definiciones-estrategicas-2/

Nora, P. (2009). Pierre Nora en Les lieux de memoire. Santiago, Chile: LOM. 
Nordenflycht, J. de. (s. f.). Cuadernos de Historia del Arte. Universidad de Chile, III Encuentro de Historia del Arte en Chile.

Prats, L. (2005). Concepto y gestión del patrimonio local, 21, 17-35.

Ramos Torre, R. (1992). Tiempo y sociedad. Madrid: Centro de Investigaciones Sociológicas : Siglo Veintiuno de España.

Richard, N. (1994). La Insubordinación de los signos: cambio político, transformaciones culturales y poéticas de la crisis. Santiago: Editorial Cuarto Propio.

Richard, N. (2010). Crítica de la memoria, 1990 - 2010 (1.ed). Santiago, Chile: Ediciones Universidad Diego Portales.

Riegl, A. (1987). El Culto moderno a los monumentos: caracteres y origen. Madrid: Machado Libros.

Schaap, A. (2005). Political reconciliation. London; New York: Routledge.

Stern, S. (2012). Memorias en construcción: los retos del pasado presente en Chile, 19892011. Anuario de la Escuela de Historia de la Universidad Nacional de Rosario, Argentina, 24 (Revista digital N³).

Sznaider, N., y Levy, D. (2002). Memory Unbound: The Holocaust and the Formation of Cosmopolitan Memory. European Journal of Social Theory, 5 (1), 87-106. 